\title{
Aerobic fitness is a potential crucial factor in protecting paralympic athletes with locomotor impairments from atherosclerotic cardiovascular risk
}

\author{
Marco Bernardi ${ }^{1,2} \cdot$ Silvio Romano $^{3}$ (i) $\cdot$ Maria Rosaria Squeo ${ }^{4}$ Emanuele Guerra ${ }^{5} \cdot$ Paolo Emilio Adami $^{6}$. \\ Federica Alviti ${ }^{7}$. Antonella Mattei ${ }^{8}$. Loretta Corsi ${ }^{1}$ - Riccardo Lanzano ${ }^{1}$ - Pietro Giacomo Curatulo ${ }^{1}$. \\ Dimitri Mandolesi ${ }^{1}$. Fabiana Parisi ${ }^{1}$ - Barbara Di Giacinto ${ }^{4}$. Donatella Dante ${ }^{1}$. Claudio Marini ${ }^{4}$. \\ Evgeny Mashkovskiy ${ }^{9} \cdot$ Francisco Javier Ordonez $^{10} \cdot$ Antonio Spataro $^{4}$
}

Received: 27 October 2019 / Accepted: 13 September 2020 / Published online: 24 December 2020

(c) The Author(s) 2020

\begin{abstract}
Purpose To test the hypothesis that aerobic fitness is inversely related to the risk of atherosclerotic cardiovascular disease (ACVD) in athletes with locomotor impairments deriving from health conditions, such as spinal cord injury (SCI), lower limb amputation, cerebral palsy, poliomyelitis, and other health conditions different from the previous ones.

Methods A total of 68 male athletes who competed in either summer or winter Paralympic games were divided in two health conditions groups ( 35 with SCI, mean age $37.2 \pm 8.0$ years, and 33 with different health conditions, mean age $37.8 \pm 9.9$ years) and in four sport type groups (skill, power, intermittent—mixed metabolism—and endurance). They were evaluated through anthropometric and blood pressure measurements, laboratory blood tests, and graded cardiopulmonary maximal arm cranking exercise test, with oxygen uptake peak $\left(V \mathrm{O}_{2 \text { peak }}\right)$ measurement. Cardiovascular risk profile was assessed in each athlete. Results The prevalence of ACVD-risk factors in the overall population was $20.6 \%$ for hypertension; $47 \%$ and $55.9 \%$ for high values of total and LDL cholesterol, respectively; $22.1 \%$ for reduce glucose tolerance; and $8.8 \%$ for obesity. No difference was found between athletes with and without SCI, while the prevalence of obesity was significantly higher in those practicing skill sports $(22.7 \%, p=0.035)$, which was the sport type group with Paralympic athletes with the lowest $V \mathrm{O}_{2 \text { peak }}$ $\left(22.5 \pm 5.70 \mathrm{ml} \mathrm{kg}^{-1} \mathrm{~min}^{-1}\right) . V \mathrm{O}_{2 \text { peak }}$ was lower in athletes with SCI than those with different health conditions $(28.6 \pm 10.0$ vs $\left.33.6 \pm 8.9 \mathrm{ml} \mathrm{kg}^{-1} \mathrm{~min}^{-1} p=0.03\right)$, and in those with $3-4$ risk factors $\left(19.09 \pm 5.34 \mathrm{ml} \mathrm{kg}^{-1} \mathrm{~min}^{-1}\right)$ than those with 2 risk factors $\left(27.1 \pm 5.50 \mathrm{ml} \mathrm{kg}^{-1} \mathrm{~min}^{-1}\right), 1$ risk factor $\left(31.6 \pm 8.55 \mathrm{ml} \mathrm{kg}^{-1} \mathrm{~min}^{-1}\right)$, or none $\left(36.4 \pm 8.76 \mathrm{ml} \mathrm{kg}^{-1} \mathrm{~min}^{-1}\right)(p<0.001)$. Conclusions The present study suggests that having higher $V \mathrm{O}_{2 \text { peak }}$ seems to offer greater protection against ACVD in individuals with a locomotor impairment. Prescribing physical exercise at an intensity similar to that of endurance and intermittent sports should become a fundamental tool to promote health among people with a locomotor impairment.
\end{abstract}

Keywords Cardiovascular primary prevention $\cdot$ Paralympic sports $\cdot$ Spinal cord injury $\cdot$ Lower limb amputation $\cdot V \mathrm{O}_{2 \text { peak }}$

Silvio Romano

silvio.romano@cc.univaq.it

1 Department of Physiology and Pharmacology "V. Erspamer", School of Specialty in Sports Medicine and Physical Exercise, "Sapienza" University of Rome, Rome, Italy

2 Italian Paralympic Committee, Rome, Italy

3 Cardiology, Department of Life, Health and Environmental Sciences, University of L'Aquila, L'Aquila, Italy

4 Institute of Sport Medicine and Science, Sport and Health, Rome, Italy
5 Sports Medicine Unit, ASL ROMA 1, Rome, Italy

6 Health and Science Department, International Association of Athletics Federations IAAF, Monaco, Monaco

7 Department of Physical Medicine and Rehabilitation, "Sapienza" University of Rome, Rome, Italy

8 Medical Statistical, Department of Life, Health and Environmental Sciences, University of L'Aquila, L'Aquila, Italy

9 Department of Sports Medicine and Medical Rehabilitation, Sechenov University, Moscow, Russia

10 School of Sports Medicine, University of Cadiz, Cadiz, Spain 


\section{Introduction}

Atherosclerotic cardiovascular disease is currently the main cause of mortality in able-bodied population [1] and in individuals with spinal cord injury (SCI) [2]. In recent years, longevity in individuals with SCI has increased significantly, although life expectancy is on average still shorter than in ambulatory individuals [2]. Indeed, ablebodied population has a lower risk of atherosclerotic cardiovascular disease (ACVD) than individuals with locomotor impairment, such as those with SCI $[3,4]$ or other health conditions such as lower limb amputation [4-6]. In particular, individuals with SCI are characterized by a higher incidence of secondary complications [7], including impaired glucose tolerance and diabetes mellitus, overweight and/or obesity [8, 9], hypertension [4], and impaired lipid profile [8], mainly because of a sedentary habit (due to immobilization caused by their health condition) and lack of physical activity [10,11].

Individuals with a locomotor impairment, and especially those with SCI, are likely to get into a vicious cycle, due to a sedentary lifestyle, that can progressively reduce their quality of life and health, accelerating muscle weakening, worsening osteoporosis, increasing the decay of cardiovascular, neurological, and endocrine functions, eventually perpetuating a condition of reduced physical work capacity and increased motor impairment and muscle hypotrophy $[12,13]$. Epidemiological studies about lifestyle and mortality of individuals after SCI demonstrate a significant positive correlation between longevity and active life [14]. An active lifestyle includes reduced sedentary behaviour (time spent sitting) and increased energy expenditure in daily life activities as well as exercise and sport. The health benefits of physical exercise, in particular aerobic training at appropriate intensities, are well documented in individuals with SCI and are traditionally documented by increased levels of cardiovascular fitness $[10,15]$ and, more recently, also by reduced oxidative stress [16] and reduced low-grade systemic inflammation [17]. This is why physical exercise is recommended for people with SCI [10] and new guidelines to improve fitness and cardio-metabolic health have been developed [18] and position statements to support physical exercise have been made [19].

In able-bodied individuals, a high level of aerobic fitness has a greater impact on ACVD than physical activity [20]. Indeed, a high aerobic fitness has been shown to be both indicative of a favorable prognosis in able-bodied individuals [20-24], and associated with longevity [25] and lower rate of both cardiovascular and all cause mortality [26]. At our best knowledge, however, the relationship between aerobic fitness and cardiovascular risk reduction is debated in individuals with SCI with low cardiovascular fitness [27-29] and it has been only suggested but not demonstrated in Paralympic Athletes [30], even though sport has been repeatedly considered and used as one of the most effective ways to improve cardiovascular fitness and provide health benefits in people with SCI [31], lower limb amputation [32], and other health conditions [30]. Nevertheless, a Brazilian study [33] and a recent Italian study [34] found in different cohorts of Paralympic Athletes a high prevalence of ACVD-risk factors. In spite of a demonstrated increased energy expenditure $[35,36]$ and its direct impact on $V \mathrm{O}_{2 \text { peak }}$ [35], some paralympic athletes are still at high risk of developing ACVD.

The aims of the present study were to test the hypothesis that in paralympic athletes with a locomotor impairment, the ACVD risk is inversely related to aerobic fitness, and to assess whether there are differences between athletes with or without SCI in these two variables. For this purpose, we evaluated 68 paralympic athletes with a locomotor impairment, competing in sports with a broad range of energy expenditure [35, 36] and aerobic fitness [37, 38].

\section{Methods}

Individuals with physical, visual, and intellectual impairments who have qualified to compete in the Paralympic Games must be evaluated for health [39] and fitness [12] to comply with Italian law [13] and Italian National Olympic Committee (CONI) rules [40] concerning sport eligibility. This pre-participation screening for individuals with an impairment, funded by the Italian Paralympic Committee (CIP), is carried out, as primary clinical care, at the Institute of Science and Medicine in Sport (CONI) in collaboration with the School of Specialty in Sports Medicine, Department of Physiology and Pharmacology, "Sapienza", University of Rome, since the 1998 Nagano Winter Paralympic Games [12].

This program is implemented in 2 days of functional, clinical, instrumental, and laboratory evaluations, which is called the Paralympic visit [12]. It is an integral part of the process required by CIP and CONI and pursuant to italian law to assess a risk-free sport eligibility before the highest level of competitive sport [13]. This assessment includes both an accurate cardiovascular screening [39] and a comprehensive fitness evaluation [37]. The Institute of Sports Medicine and Science, division of CONI, is responsible for the elite Italian athletes, from which participants to either Olympic or Paralympic Games are selected. A complete evaluation of the presence of modifiable ACVD risk factors and measurement of aerobic fitness was possible in a retrospective way in paralympic athletes of our series. 
Each athlete's "Paralympic Visit" consists of several clinical and functional evaluations performed over a 2-day period. These include: blood and urine laboratory examinations; general clinical and cardiovascular examination including blood pressure (BP) measurement; anthropometry and body composition evaluation including skin-fold measurements; classification evaluation to assess impairment and level of lesion [https://www.paralympic.orgl]; a nutritional evaluation to assess energy intake and percentage of macronutrient distribution through a $24 \mathrm{~h}$ diet recall interview; cardiologic visit, basal ECG and echo-color cardiac Doppler, graded continuous arm cranking ergometer, maximal cardiopulmonary integrated exercise test (which includes ECG) to assess possible cardiovascular disorders [39] and to assess $V \mathrm{O}_{\text {2peak }}$ [37]; orthopedic visit; otolaryngology visit; neurological visit; psycho-diagnostic and sport related psychological evaluation; pulmonary evaluation with spirometry; ophthalmological visit. Through the cardiopulmonary integrated exercise test, aerobic fitness is evaluated, measuring not only $V \mathrm{O}_{2 \text { peak }}$ but also ventilatory threshold and respiratory compensation point [41] (if necessary should are also effectuated: muscle-tendon ultrasounds and radiography, nutritional prescription; internist hepatological and infective evaluations; cardiologic therapies, Holter ECG, and ambulatory blood pressure monitoring). During the afternoon of the first day of the paralympic visit and during the second day upper and lower limb strength, explosive power and anaerobic capacity were also evaluated [42], using functional tests with ergometer specific to each sport discipline (e.g., treadmill for standing runners, rowing ergometers for rowers, and cycle ergometer for cyclists).

For the purpose of the present study, all paralympic athletes were screened through anthropometry, BP measurements, and blood tests. In accordance with the Declaration of Helsinki, each athlete had provided written informed consent for participation. Only male subjects were enrolled, with the aim of evaluating a more homogeneous population, avoiding female subjects who may differ in cardiovascular risk due to hormonal status and generally have lower $V \mathrm{O}_{2 \text { peak }}$ values than male subjects.

The presence of cardiovascular risk factors that could be modified by physical activity and aerobic fitness was established defining an ACVD-risk factors score by adding 1 point for each positive factor and subtracting 1 point when serum high-density lipoprotein cholesterol (HDL-C) was higher than $60 \mathrm{mg} \mathrm{dl}^{-1}$. These risk factors were evaluated: hypertension, dyslipidemia, impaired fasting glucose, and obesity.

Blood pressure (BP) was measured with a properly calibrated and validated sphygmomanometer in a secluded room. Athletes sat quietly in a chair for at least $5 \mathrm{~min}$. At least three measurements were taken with the arm supported at heart level. Criteria for hypertension were: systolic blood pressure (SBP) $\geq 140 \mathrm{mmHg}$ and/or diastolic blood pressure (DBP) $\geq 90 \mathrm{mmHg}$ [42] in all measurements, and confirmed by $24 \mathrm{~h}$ ambulatory monitoring.

Laboratory blood tests included glucose, total cholesterol (C), low-density lipoprotein cholesterol (LDL-C), and HDL-C. A $15 \mathrm{ml}$ venous blood sample was drawn from the antecubital vein after a $12 \mathrm{~h}$-long fasting period. Samples were analyzed using automated colorimetric and fluorimetric methods. Dyslipidemia criteria were: HDLcholesterol $\leq 40 \mathrm{mg} \cdot \mathrm{dl}^{-1}$ or LDL-C $\geq 130 \mathrm{mg} \mathrm{dl}^{-1}$ or total $\mathrm{C} \geq 200 \mathrm{mg} \mathrm{dl}^{-1}$. A fasting plasma glucose concentration $\geq 126 \mathrm{mg} \mathrm{dl}^{-1}$ was considered diagnostic of diabetes mellitus; a glucose concentration ranging from 100 to $125 \mathrm{mg} \mathrm{dl}^{-1}$ was classified as impaired fasting glucose.

Body mass and height were measured using standard equipment and were used to determinate body mass index (BMI). Individuals were classified as obese if their BMI was $\geq 30 \mathrm{~kg} / \mathrm{m}^{2}$ [43] or if their waist circumference was $\geq$ $102 \mathrm{~cm}$. Waist circumference measurements were taken with a flexible yet inelastic tape measure placed on the skin surface at umbilicus level without compressing the subcutaneous adipose tissue with the subject standing (if possible) or sitting on the examination table, arms at the sides, feet together, and abdomen relaxed.

Based on the presence of ACVD-risk factors, paralympic athletes were subdivided in 4 groups: group 1 with no ACVD-risk factors, group 2 with light-moderate ACVDrisk (1 risk factor), group 3 with moderate-high ACVD risk (2 risk factors); group 4 with very high ACVD risk ( $>2$ risk factors).

To measure $V \mathrm{O}_{\text {2peak }}$, while assessing the exercise ECG, each paralympic athlete was submitted to an incremental, continuous, multistage exercise test, protracted to volitional exhaustion carried through an arm cranking ergometer (ER800Sh, Cosmed Italy), monitoring through a breath by breath analyser (Quark CPET, Cosmed, Rome, Italy): pulmonary ventilation, oxygen uptake, carbon dioxide production, and heart rate $[12,37]$. The test consisted of a $3 \mathrm{~min}$ warm-up phase carried out in a ramp fashion to reach a power ranging between 30 and 50 watts $(\mathrm{W})$, followed by a ramp exercise phase with increments of 10 or $15 \mathrm{~W}$ every minute. The power increments in both warm-up and exercise phases depended on the level of lesion, the practiced sport, and the estimated aerobic fitness of the Paralympic athletes. The selection of the different power increments was aimed at allowing a $10 \mathrm{~min}$-long exercise phase [35]. Three criteria were used to assess the achieving of $V \mathrm{O}_{2 \text { peak }}$, i.e. the cardiopulmonary exercise test end points: (1) a levelling off or a decline in the $V \mathrm{O}_{2}$ with increasing power output, (2) HR equivalent to at least $95 \%$ of the age predicted maximum (220 — age, years), and (3) respiratory exchange ratio $(\mathrm{RER}) \geq 1.10$. Two of these three criteria had to be met. 
After the test, a lactic acid value $>8 \mathrm{mmol} / \mathrm{l}$ confirmed that peak $V \mathrm{O}_{2}$ was attained.

Anthropometric measurements and data from blood tests and cardiopulmonary exercise tests from the pre-participation screenings carried out in individuals with locomotor impairment (spinal cord injury or other health conditions) before the 2008 Beijing Summer Paralympic Games and 2010 Vancouver Winter Paralympic Games were analyzed retrospectively for the present study.

\section{Data analysis}

Descriptive analyses were used to illustrate the characteristics of the sample. The discrete and nominal variables were described through frequencies and percentages and the difference between subgroups was assessed with the Chi-square test. The quantitative variables were expressed in terms of mean and standard deviation (sd), whose significance was assessed with a $t$ test for independent samples. The differences between type of sports and ACDV risk factor groups were assessed with one-way ANOVA test and post hoc analysis was assessed with Bonferroni test. A $p$ value of $<0.05$ was the criterion for statistical significance. The data were processed using the STATA/IC15.0 statistical package.

\section{Results}

The database included a total of 68 male Paralympic athletes (age $37.5 \pm 8.9$ years, body mass $73.5 \pm 15.5 \mathrm{~kg}$ and height $1.76 \pm 0.086 \mathrm{~m})$ with different health conditions: $35(51.5 \%)$ had a SCI (paraplegia), 19 (27.9\%) had a lower limb amputation, 4 (5.9\%) had a lower limb cerebral palsy, 3 (4.4\%) had lower limb poliomyelitis sequelae, and $7(10.3 \%)$ had a locomotor impairment deriving from other neurological or orthopedic disorders ("Les Autres"- the others). Table 1 shows age, anthropometric characteristics, and aerobic fitness of the sample divided by health condition (SCI or other disorders). Significant differences were found in the two health conditions groups for $V \mathrm{O}_{\text {2peak }}$ in absolute and relative values.

The types of sport were divided in the following 4 groups as previously reported [39] and on the basis of both biomechanical [37, 44] and energy expenditure studies [36, 37, 45]: skill sports, power sports, mixed sports, meaning intermittent sports with aerobic and anaerobic alternated metabolism, and endurance sports. Paralympic athletes competing in skill sports included sailors, shooters, table tennis players, curlers, and those competing in archery and in equestrians. Paralympic athletes competing in power sports included: alpine skiers and those competing in field events (throwing sports, long jump, and short distance track events). Paralympic athletes competing in mixed sports included fencers, wheelchair tennis players, and those competing in ice sledge hockey. Paralympic athletes competing in endurance sports included swimmers, hand-cyclists, nordic skiers, and those competing in long-distance track events. Among the paralympic athletes with SCI and those with other Health Conditions, 14 and 8 competed in skill sports, 5 and 7 in power sports, 7 and 13 in mixed sports, and 9 and 5 in endurance sports, respectively.

Table 2 shows the characteristics of the paralympic athletes on the basis on of the practiced sport. Age and BMI were significantly different only between paralympic athletes competing in skill sports and endurance sports, while there were relevant differences in $V \mathrm{O}_{2 \text { peak }}$ between all groups: paralympic athletes competing in skill sports showed significantly lower $V \mathrm{O}_{2 \text { peak }}$ values vs all the other sport groups as well as paralympic athletes competing in endurance sports showed significantly higher $V \mathrm{O}_{2 \text { peak }}$ values vs all the other sport groups. Indeed, paralympic athletes competing in endurance sports displayed the highest $V \mathrm{O}_{2 \text { peak }}$ values, almost the double of those of paralympic athletes competing in skill sports.
Table 1 Age, anthropometrical variables, and aerobic fitness of the athletes divided by health condition

\begin{tabular}{|c|c|c|c|c|}
\hline & $\begin{array}{l}\text { Total } \\
n(\%) \\
68(100)\end{array}$ & $\begin{array}{l}\text { SCI } \\
n(\%) \\
35(51.5)\end{array}$ & $\begin{array}{l}\text { Other health } \\
\text { conditions } \\
n(\%) \\
33(48.5)\end{array}$ & $p$ value \\
\hline Age (years) & $37.5 \pm 8.9$ & $37.2 \pm 8.0$ & $37.8 \pm 9.9$ & 0.75 \\
\hline Body mass (kg) & $73.5 \pm 15.5$ & $74.1 \pm 18.9$ & $73.0 \pm 10.9$ & 0.77 \\
\hline Height (m) & $1.76 \pm 0.09$ & $1.77 \pm 0.09$ & $1.76 \pm 0.08$ & 0.38 \\
\hline BMI $\left(\mathrm{kg} / \mathrm{m}^{2}\right)$ & $23.2 \pm 4.9$ & $23.6 \pm 5.1$ & $22.8 \pm 4.9$ & 0.92 \\
\hline$V \mathrm{O}_{2 \text { peak }}$ absolute value $\left(\mathrm{ml} \mathrm{min}{ }^{-1}\right)$ & $2203 \pm 582$ & $2015 \pm 556$ & $2400 \pm 549$ & $0.005^{*}$ \\
\hline $\mathrm{VO}_{2 \text { peak }}$ relative value $\left(\mathrm{ml} \mathrm{kg}^{-1} \mathrm{~min}^{-1}\right)$ & $31.0 \pm 9.7$ & $28.6 \pm 10.0$ & $33.6 \pm 8.9$ & $0.03^{*}$ \\
\hline
\end{tabular}


Table 2 Age, anthropometrical variables and aerobic fitness of the athletes divided by type of sport

\begin{tabular}{|c|c|c|c|c|c|}
\hline & $\begin{array}{l}\text { Skill sports (1) } \\
n(\%) \\
22(32.4)\end{array}$ & $\begin{array}{l}\text { Power sports (2) } \\
n(\%) \\
12(17.6)\end{array}$ & $\begin{array}{l}\text { Mixed sports (3) } \\
\mathrm{n}(\%) \\
20(29.4)\end{array}$ & $\begin{array}{l}\text { Endurance sports (4) } \\
n(\%) \\
14(20.6)\end{array}$ & $p$ value \\
\hline Age (years) & $41.9 \pm 7.8$ & $36.5 \pm 7.7$ & $37.6 \pm 8.3$ & $31.2 \pm 9.3$ & $0.003 *$ \\
\hline Body mass $(\mathrm{kg})$ & $77.6 \pm 20.0$ & $74.5 \pm 17.0$ & $73.7 \pm 9.7$ & $66.1 \pm 10.8$ & 0.193 \\
\hline Height (m) & $1.75 \pm 0.11$ & $1.78 \pm 0.08$ & $1.78 \pm 0.06$ & $1.76 \pm 0.08$ & 0.627 \\
\hline BMI $\left(\mathrm{kg} / \mathrm{m}^{2}\right)$ & $25.4 \pm 5.2$ & $23.3 \pm 4.0$ & $22.2 \pm 5.7$ & $21.2 \pm 2.7$ & $0.026^{*}$ \\
\hline$V \mathrm{O}_{2 \text { peak }}$ absolute value $\left(\mathrm{ml} \mathrm{min}^{-1}\right)$ & $1667 \pm 282$ & $2267 \pm 475$ & $2401 \pm 460$ & $2706 \pm 545$ & $<0.001^{*}$ \\
\hline \multirow[t]{3}{*}{$V \mathrm{O}_{2 \text { peak }}$ relative value $\left(\mathrm{ml} \mathrm{kg}^{-1} \min ^{-1}\right)$} & $22.5 \pm 5.7$ & $31.7 \pm 8.8$ & $32.6 \pm 4.3$ & $41.7 \pm 9.6$ & $<0.001^{*}$ \\
\hline & \multicolumn{5}{|c|}{ Post hoc analysis } \\
\hline & 1 vs 2 & 1 vs 3 & 1 vs 4 & 2 vs 4 & 3 vs 4 \\
\hline Age & 0.442 & 0.528 & 0.002 & 0.612 & 1.00 \\
\hline BMI $\left(\mathrm{kg} / \mathrm{m}^{2}\right)$ & 0.901 & 0.620 & $0.017 *$ & 1.00 & 0.710 \\
\hline$V \mathrm{O}_{2 \text { peak }}$ absolute value $\left(\mathrm{ml} \mathrm{min}^{-1}\right)$ & $0.002 *$ & $<0.001 *$ & $<0.001^{*}$ & 0.289 & 0.289 \\
\hline$V \mathrm{O}_{2 \text { peak }}$ relative value $\left(\mathrm{ml} \mathrm{kg}^{-1} \min ^{-1}\right)$ & $0.003^{*}$ & $<0.001 *$ & $<0.001^{*}$ & $0.003^{*}$ & $0.002 *$ \\
\hline
\end{tabular}

One-way ANOVA test (post hoc tests using Bonferroni's correction)

$* p$ value $<0.05$

Tables 3 and 4 show for each ACVD-risk factors the mean value and the standard deviation in the whole sample and dividing it by different health conditions and by the four types of sport. No difference was found between paralympic athletes with SCI vs those with other Health Conditions, while, based on post hoc analysis, fasting blood glucose and abdomen circumference showed higher values in the Paralympic athletes competing in skill sports, vs power sports and mixed sports, respectively.

As shown in Tables 5 and 6, we also evaluated the prevalence of each ACVD-risk factors in the whole population dividing it by different health conditions and by the four types of sport. No difference was found between paralympic athletes with SCI vs those with other Health Conditions, while, considering the type of sport, only obesity showed a different prevalence, higher in skill and power sports (77.3\% and $91.7 \%$, respectively) and absent in mixed and endurance sports.

Finally, based on the number of ACVD risk factors found in each paralympic athlete, four groups were identified by calculating the ACVD-risk factor score, as described in the Methods section: group 1 (score $\leq 0$, $N=23)$, group 2 ( $\operatorname{score}=1, N=26)$, group 3 (score $=2$, $N=10)$, and group $4($ score $>2, N=9)$. Table 7 shows the pertinent characteristics of the four aforementioned groups: the paralympic athletes with higher score (group 4) were older and showed a higher BMI, while the paralympic athletes with a favorable score (group 1 and 2) showed a better aerobic fitness rather than the other groups.
Table 3 Value of risk factors of the athletes divided by health condition

\begin{tabular}{lcccc}
\hline & $\begin{array}{l}\text { Total } \\
n(\%)\end{array}$ & $\begin{array}{l}\text { SCI } \\
n(\%)\end{array}$ & $\begin{array}{l}\text { Other health conditions } \\
n(\%)\end{array}$ & $p$ value \\
& $68(100)$ & $35(51.5)$ & $33(48.5)$ & \\
\hline SBP (mmHg) & $126.5 \pm 9.9$ & $127.3 \pm 9.5$ & $125.8 \pm 10.4$ & 0.52 \\
DBP (mmHg) & $80.8 \pm 6.8$ & $80.6 \pm 6.0$ & $81.1 \pm 7.6$ & 0.76 \\
TOTAL COL (mg/dl) & $205.9 \pm 44.3$ & $207.9 \pm 43.1$ & $203.9 \pm 46.0$ & 0.72 \\
HDL COL (mg/dl) & $50.9 \pm 14.5$ & $49.8 \pm 13.9$ & $52.0 \pm 15.3$ & 0.54 \\
LDL COL (mg/dl) & $131.5 \pm 37.8$ & $132.0 \pm 36.6$ & $130.9 \pm 39.4$ & 0.90 \\
Fasting blood glucose (mg/dl) & $95.7 \pm 9.6$ & $96.3 \pm 11.8$ & $94.9 \pm 6.9$ & 0.55 \\
Abdomen circ $(\mathrm{cm})$ & $93.1 \pm 17.1$ & $95.5 \pm 20.1$ & $90.8 \pm 13.5$ & 0.27 \\
\hline
\end{tabular}

$p$ value using independent $t$ test 
Table 4 Value of risk factors of the athletes divided by type of sport

\begin{tabular}{|c|c|c|c|c|c|}
\hline & $\begin{array}{l}\text { Skill sports (1) } \\
n(\%) \\
22(32.4)\end{array}$ & $\begin{array}{l}\text { Power sports }(2) \\
n(\%) \\
12(17.6)\end{array}$ & $\begin{array}{l}\text { Mixed sports (3) } \\
n(\%) \\
20(29.4)\end{array}$ & $\begin{array}{l}\text { Endurance sports (4) } \\
n(\%) \\
14(20.6)\end{array}$ & $p$ value \\
\hline $\mathrm{SBP}(\mathrm{mmHg})$ & $126.4 \pm 8.4$ & $126.7 \pm 11.3$ & $127.2 \pm 10.9$ & $125.7 \pm 10.7$ & 0.977 \\
\hline $\mathrm{DBP}(\mathrm{mmHg})$ & $81.4 \pm 6.4$ & $83.3 \pm 6.8$ & $79.2 \pm 8.3$ & $80.0 \pm 4.4$ & 0.388 \\
\hline HDL COL (mg/dl) & $48.9 \pm 19.0$ & $51.4 \pm 12.6$ & $48.6 \pm 10.9$ & $56.9 \pm 11.7$ & 0.353 \\
\hline LDL COL (mg/dl) & $139.2 \pm 36.4$ & $118.1 \pm 40.3$ & $138.8 \pm 40.6$ & $119.9 \pm 31.3$ & 0.256 \\
\hline Fasting blood glucose (mg/dl) & $100.9 \pm 11.9$ & $88.1 \pm 7.4$ & $95.6 \pm 5.7$ & $93.5 \pm 7.3$ & $0.001 *$ \\
\hline \multirow[t]{3}{*}{ Abdomen circ $(\mathrm{cm})$} & $101.9 \pm 21.7$ & $89.6 \pm 16.1$ & $94.1 \pm 12.3$ & $82.4 \pm 7.4$ & $0.007 *$ \\
\hline & \multicolumn{5}{|l|}{ Post hoc analysis } \\
\hline & 1 vs 2 & 1 vs 3 & 1 vs 4 & 2 vs 4 & 3 vs 4 \\
\hline Fasting blood glucose (mg/dl) & $0.001 *$ & 0.340 & 0.101 & 0.787 & 1.00 \\
\hline Abdomen circ (cm) & 0.226 & 0.760 & $0.005^{*}$ & 1.00 & 0.245 \\
\hline
\end{tabular}

One-way ANOVA test (post hoc tests using Bonferroni's correction)

$* p$ value $<0.05$

Table 5 Prevalence of ACVD risk factors in the whole sample of paralympic athletes and in the subgroups divided by health condition

\begin{tabular}{|c|c|c|c|c|}
\hline ACVD-risk factors & $\begin{array}{l}\text { Total } \\
n(\%) \\
68(100)\end{array}$ & $\begin{array}{l}\text { SCI } \\
n(\%) \\
35(51.5)\end{array}$ & $\begin{array}{l}\text { Other health } \\
\text { conditions } \\
n(\%) \\
33(48.5)\end{array}$ & $p$ value \\
\hline Hypertension & & & & 0.469 \\
\hline Absent & $54(79.4)$ & $29(82.9)$ & $25(75.8)$ & \\
\hline Present & $14(20.6)$ & $6(17.1)$ & $8(24.2)$ & \\
\hline High total cholesterol & & & & 0.797 \\
\hline Absent & $36(53.0)$ & $18(51.4)$ & $18(54.5)$ & \\
\hline Present & $32(47.0)$ & 17 (48.6) & $15(45.5)$ & \\
\hline High LDL cholesterol & & & & 0.829 \\
\hline Absent & $30(44.1)$ & $15(42.9)$ & $15(45.5)$ & \\
\hline Present & $38(55.9)$ & $20(57.1)$ & $18(54.5)$ & \\
\hline Low HDL-cholesterol & & & & 0.250 \\
\hline Absent & $47(69.1)$ & $22(62.9)$ & $25(75.8)$ & \\
\hline Present & $21(30.9)$ & $13(37.1)$ & $8(24.2)$ & \\
\hline $\begin{array}{l}\text { Reduced glucose } \\
\text { tolerance (impaired } \\
\text { fasting glucose) }\end{array}$ & & & & 0.870 \\
\hline Absent & $53(77.9)$ & $27(77.1)$ & $26(78.8)$ & \\
\hline Present & $15(22.1)$ & $8(22.8)$ & $7(21.2)$ & \\
\hline Obesity & & & & 0.102 \\
\hline Absent & $62(91.2)$ & $30(85.7)$ & $32(97.0)$ & \\
\hline Present & $6(8.8)$ & $5(14.3)$ & $1(3.0)$ & \\
\hline
\end{tabular}

$p$ value using Chi-square or Fisher's test

\section{Discussion}

The present study shows that paralympic athletes with locomotor impairment characterized by high aerobic fitness levels $\left(V \mathrm{O}_{2 \text { peak }} 42 \pm 9.6 \mathrm{ml} \mathrm{kg}^{-1} \mathrm{~min}^{-1}\right)$ and competing in endurance sport have a better ACVD-risk profile, in particular lower fasting blood glucose and abdomen circumference (even if dietary habits are not reported in this study), than paralympic athletes with locomotor impairment competing in other kinds of sports. Paralympic athletes with locomotor impairment competing in skill sports, on the other hand, are characterized by low levels of aerobic fitness $\left(V \mathrm{O}_{2 \text { peak }}\right.$ $22 \pm 5.7 \mathrm{ml} \mathrm{kg}^{-1} \mathrm{~min}^{-1}$ ) and have higher fasting blood glucose and greater abdomen circumference. Indeed, dividing the population of the present study in four groups of ACVD-risk factors, paralympic athletes without ACVDrisk factors displayed the highest $V \mathrm{O}_{2 \text { peak }}$ values $\left(V \mathrm{O}_{2 \text { peak }}\right.$ $36 \pm 8.8 \mathrm{ml} \mathrm{kg}^{-1} \mathrm{~min}^{-1}$ ), while paralympic athletes with the highest ACVD- risk factors score show the lowest levels of $V O_{2 \text { peak }}\left(19 \pm 5.3 \mathrm{ml} \mathrm{kg}^{-1} \mathrm{~min}^{-1}\right)$. High-level physical activity, therefore, seems to reduce the incidence of risk factors for ACVD, both in subjects with SCI and with other Health Conditions.

Numerous literature data show that individuals with SCI have a higher risk for ACVD, due to several mechanisms: (1) blood pressure abnormalities [46, 47] caused by the compromised sympathetic nervous system response below the level of injury (chronically low arterial blood pressure at rest and orthostatic hypotension, and autonomic dysreflexia); (2) physical inactivity and obesity (increase in fat mass together with sarcopenia) [10]. Indeed, the alterations of both the motor and the autonomic sympathetic nervous system, the physical inactivity, and the forced 
Table 6 Prevalence of ACVD risk factors in paralympic athletes divided by type of sport

\begin{tabular}{|c|c|c|c|c|c|}
\hline ACVD risk factors & $\begin{array}{l}\text { Skill sports (1) } \\
n(\%) \\
22(32.4)\end{array}$ & $\begin{array}{l}\text { Power sports (2) } \\
n(\%) \\
12(17.6)\end{array}$ & $\begin{array}{l}\text { Mixed sports (3) } \\
n(\%) \\
20(29.4)\end{array}$ & $\begin{array}{l}\text { Endurance sports (4) } \\
n(\%) \\
14(20.6)\end{array}$ & $p$ value \\
\hline Hypertension & & & & & 0.574 \\
\hline Absent & $17(77.3)$ & $9(75.0)$ & $15(75.0)$ & $13(92.9)$ & \\
\hline Present & $5(22.7)$ & $3(25.0)$ & $5(25.0)$ & $1(7.1)$ & \\
\hline High total cholesterol & & & & & 0.183 \\
\hline Absent & $9(40.9)$ & $9(75.0)$ & $9(45.0)$ & $9(64.3)$ & \\
\hline Present & $13(59.1)$ & $3(25.0)$ & $11(55.0)$ & $5(35.7)$ & \\
\hline High LDL cholesterol & & & & & 0.057 \\
\hline Absent & $6(27.3)$ & $9(75.0)$ & $8(40.0)$ & $7(50.0)$ & \\
\hline Present & $16(72.7)$ & $3(25.0)$ & $12(60.0)$ & $7(50.0)$ & \\
\hline High HDL-cholesterol & & & & & 0.352 \\
\hline Absent & $13(59.1)$ & $9(75.0)$ & $15(75.0)$ & $12(85.7)$ & \\
\hline Present & $9(40.9)$ & $3(25.0)$ & $5(25.0)$ & $2(14.3)$ & \\
\hline $\begin{array}{l}\text { Reduced glucose tolerance } \\
\quad \text { (impaired fasting glucose) }\end{array}$ & & & & & 0.086 \\
\hline Absent & $14(63.6)$ & $12(100.0)$ & $15(75.0)$ & $12(85.7)$ & \\
\hline Present & $8(36.4)$ & $0(0.0)$ & $5(25.0)$ & $2(14.3)$ & \\
\hline Obesity & & & & & $0.035^{*}$ \\
\hline Absent & $17(77.3)$ & $11(91.7)$ & $20(100.0)$ & $14(100.0)$ & \\
\hline Present & $5(22.7)$ & $1(8.3)$ & $0(0.0)$ & $0(0.0)$ & \\
\hline
\end{tabular}

$p$ value using Chi-square or Fisher's test ( $* p$ value $<0.05)$

Table 7 Age, anthropometrical characteristics, and aerobic fitness of the athletes divided by the four groups of ACVD-risk factor score

\begin{tabular}{|c|c|c|c|c|c|c|}
\hline & & \multicolumn{4}{|c|}{ ACVD-risk factor groups } & \multirow[t]{2}{*}{$p$ value } \\
\hline & & $\begin{array}{l}\text { Score } \leq 0 \\
(\text { group } 1) \\
n=23\end{array}$ & $\begin{array}{l}\text { Score }=1 \\
(\text { group 2) } \\
n=26\end{array}$ & $\begin{array}{l}\text { Score }=2(\text { group } 3) \\
n=10\end{array}$ & $\begin{array}{l}\text { Score }>2 \\
\text { (group 4) } \\
n=9\end{array}$ & \\
\hline \multicolumn{2}{|l|}{ Age (years) } & $35.2 \pm 8.5$ & $36.6 \pm 9.6$ & $37.6 \pm 5.7$ & $45 \pm 7.3$ & $0.0027 *$ \\
\hline \multicolumn{2}{|l|}{ Body mass (kg) } & $66.2 \pm 10.3$ & $74.5 \pm 12.84$ & $79.6 \pm 12.4$ & $93.3 \pm 20.24$ & $<0.001 *$ \\
\hline \multicolumn{2}{|l|}{ Height (m) } & $1.8 \pm 0.09$ & $1.7 \pm 0.19$ & $1.8 \pm 0.09$ & $1.8 \pm 0.08$ & 0.185 \\
\hline \multicolumn{2}{|l|}{ BMI $\left(\mathrm{kg} / \mathrm{m}^{2}\right)$} & $21.0 \pm 2.71$ & $26.5 \pm 14.81$ & $25.4 \pm 3.38$ & $29.3 \pm 4.14$ & $<0.001 *$ \\
\hline \multirow{2}{*}{\multicolumn{2}{|c|}{$\begin{array}{l}V \mathrm{O}_{2 \text { peak, }} \text { absolute value }(\mathrm{ml} \mathrm{min}-1) \\
V \mathrm{O}_{2 \text { peak, }} \text { relative value }\left(\mathrm{ml} \mathrm{kg}^{-1} \min ^{-1)}\right.\end{array}$}} & $2346 \pm 665$ & $2287 \pm 556$ & $1985 \pm 440$ & $1785 \pm 400$ & 0.072 \\
\hline & & $36.4 \pm 8.76$ & $31.6 \pm 8.55$ & $27.1 \pm 5.50$ & $19.09 \pm 5.34$ & $<0.001^{*}$ \\
\hline & \multicolumn{4}{|c|}{ Post hoc analysis } & & \\
\hline & Group 1 vs 2 & Group 1 vs 3 & Group 1 vs 4 & Group 2 vs 3 & Group 2 vs 4 & Group 3 vs 4 \\
\hline Age & 1.00 & 0.07 & $0.006^{*}$ & 0.385 & $0.041^{*}$ & 1.00 \\
\hline Body mass & 0.108 & 0.518 & $<0.000^{*}$ & 1.00 & $<0.001 *$ & $<0.001 *$ \\
\hline BMI & $0.013^{*}$ & $0.003 *$ & $<0.000 *$ & 1.00 & $<0.000 *$ & $0.003 *$ \\
\hline$V \mathrm{O}_{\text {2peak, }}$, relative value & 0.307 & $0.032 *$ & $<0.000^{*}$ & 0.977 & $0.002 *$ & 0.261 \\
\hline
\end{tabular}

One-way ANOVA test (post hoc analysis using Bonferroni's correction)

$* p<0.05$

sedentariness consequent to the lesion predispose the SCI patients to an excessive abdominal obesity [10]; (3) oxidative stress [16] and low-grade chronic systemic inflammation, also determined by the attenuation of the lipolysis resulting from the reduced sympathetic stimulation and the increased macrophage infiltration of the lipid tissue [17] with elevated plasma $\mathrm{C}$-reactive protein concentration; (4) 
increased prevalence of smoking [48]; (5) dyslipidemia, insulin resistance, and type 2 diabetes $[3,9,10]$.

Furthermore, clinical manifestations, i.e., deep vein thrombosis, thrombo-embolic events, rhythm disturbances (bradycardia, A-V block and cardiac arrest, particularly in the acute phase), reduced heart rate variability [49], blunted cardiovascular response to exercise [10,30], and premature death [14] have been detected in individuals with SCI.

Sport practice may interrupt the hypotrophy-sedentary habit-further hypotrophy vicious cycle and is considered the best way for improving physical fitness in individuals with locomotor impairment [30, 31], preventing harmful habits such as alcoholism, smoking use, drug addiction, and excessive food consumption, thus reducing the risk of cardiovascular diseases [15]. Furthermore, several studies demonstrated important increases in $V \mathrm{O}_{2 \text { peak }}$ after arm cranking ergometry, wheelchair ergometry, and swimming conditioning program training [10], evidence that even people with SCI can obtain health and mental benefits. However, evidence-based scientific guidelines for specific population, for example for individuals with SCI, should be followed, to improve fitness and cardiac and metabolic health, with appropriate frequencies, intensities, types, and duration of exercise, and, therefore, training volumes.

However, a high prevalence of ACVD-risk factors was even found both in a group of brazilian paralympic athletes (67 with physical and 12 with visual impairment), including 11 with SCI, 6 with lower limb deficiency, 27 with poliomyelitis sequelae, and 21 with cerebral palsy [33], and in 50 elite italian paralympic athletes competing in summer and winter games including athletes with SCI, lower limb amputation $(n=15)$, and upper limb impairments $(n=10)$ [34]. Also in the present study, the prevalence of ACVDrisk factors was considerably high, having about $2 / 3$ of the sample at least 1 ACVD-risk factor, while $28 \%$ had 2 or more ACVD- risk factors, confirming that the prevalence of modifiable ACVD-risk factor in paralympic athletes with locomotor impairment is relevant, as already stated $[33,34]$. The comparison between paralympic athletes with SCI and those with other Health Conditions did not find any significant difference in both absolute values and prevalence of the modifiable ACVD-risk factors. The two groups, however, in spite of the same age and anthropometric characteristics, showed significant difference in aerobic fitness. Paralympic athletes with SCI displayed a $V \mathrm{O}_{2 \text { peak }}$ equal to $29 \pm 10.0 \mathrm{ml} \mathrm{kg}^{-1} \mathrm{~min}^{-1}$, while paralympic athletes with other Health Conditions displayed a $V \mathrm{O}_{2 \text { peak }}$ equal to $34 \pm 8.9 \mathrm{ml} \mathrm{kg}^{-1} \mathrm{~min}^{-1}$. This difference could be only due to the sport participation (40\% of paralympic athletes with SCI practiced skill sports vs $24.4 \%$ of paralympic athletes with other Health Conditions), being clear from the literature that there is a significant impact of the practiced sport on the aerobic fitness [35, 37].
The present study, however, adds to the scientific literature the concept, not yet proven in this specific population, that having a high level of aerobic fitness seems protective against the ACVD risk. Indeed, 39\% of the paralympic athletes with locomotor impairment of the present study did not have any ACVD-risk factor and their $V \mathrm{O}_{2 \text { peak }}$ was significantly higher than the other paralympic athletes with locomotor impairment.

Therefore, our results show a link between aerobic fitness, which is closely related to the type of practiced sport [37], and the cardiovascular risk profile. In fact, paralympic athletes practicing skill sports have significantly lower relative and absolute values of $V \mathrm{O}_{2 \text { peak }}$ and higher BMI, fasting blood glucose, and abdomen circumferences rather than paralympic athletes practicing the other sports (Tables 2, 5, 6). Furthermore, paralympic athletes with very high-risk profile (Group 4) prevalently practice skill sports, characterized by a low energy expenditure (i.e., curling, table tennis, shooting, and archery), and show $V \mathrm{O}_{2 \text { peak }}$ values significantly lower than those of paralympic athletes of the other three groups (Table 7). On the other hand, paralympic athletes included in Group 1 (no risk factor) have the highest $V \mathrm{O}_{2 \text { peak }}$ values and mainly compete in endurance sports, such as long-distance wheelchair racing, nordic skiing, hand-bike, or sports with massive components of aerobic and lactic anaerobic metabolisms such as swimming and rowing, here included among the endurance sports. The $V \mathrm{O}_{2 \text { peak }}$ is, therefore, inversely related to the atherosclerotic cardiovascular risk score in paralympic athletes with locomotor impairment, suggesting that aerobic fitness may provide a protective effect against cardiovascular disease. A comparison between our results and those found in healthy able-bodied individuals shows an interesting observation: the average $V \mathrm{O}_{2 \text { peak }}$ values in ablebodied individuals without ACVD-risk factors vary from 35 to $38 \mathrm{ml} \mathrm{kg}^{-1} \mathrm{~min}^{-1}$ [20, 23, 24] and are similar to those found in our athletes with locomotor impairment and no cardiovascular risk $\left(36 \pm 9 \mathrm{ml} \mathrm{kg}^{-1} \mathrm{~min}^{-1}\right)$. Therefore, it could be deduced that the same aerobic fitness reference values include individuals without cardiovascular risk factors.

Recently Nightingale et al. [28] observed that, in untrained individuals with SCI, ACVD-risk factors are associated more with body composition (higher body fat content) rather than physical activity, evaluated by $V \mathrm{O}_{2 \text { peak }}$ as expression of a significant moderate-to-vigorous physical activity (>140 min/week). The Authors stress that energy intake is more important than energy expenditure in the regulation of a healthy energy balance. Although we did not evaluate energy intake (nutrition) in our study, its relevance could be confirmed by the high prevalence of dyslipidemia. We agree that in a comprehensive physical fitness [50] and health [51] evaluation, nutrition (micro and macronutrient intake) should be accurately prescribed [52] and specific advice should be provided to the athletes to improve their dietary 
habit [51]. However, the lack of positive effects of physical activity on cardiovascular risk profile, observed by Nightingale et al. [28] and in other reports [29,53], is probably due to the lower aerobic fitness. In fact, among our individuals, who were paralympic athletes (while Nightingale and coauthors evaluated untrained individuals), those without ACVD risk had $V O_{2 \text { peak }}$ values $\left(36.4 \pm 8.76 \mathrm{ml} \mathrm{kg}^{-1} \mathrm{~min}^{-1}\right)$ much higher than the individuals evaluated by Nightingale et al. $\left(19.8 \pm 6.4 \mathrm{ml} \mathrm{kg}^{-1} \mathrm{~min}^{-1}\right)$, who showed $V \mathrm{O}_{2 \text { peak }}$ similar to our paralympic athletes with very high ACVD risk $\left(19.1 \pm 5.34 \mathrm{ml} \mathrm{kg}{ }^{-1} \mathrm{~min}^{-1}\right)$. Therefore, it can be considered that a high level of aerobic fitness is necessary to affect the ACVD-risk profile in individuals with locomotor impairment.

Other studies confirm this consideration. Noreau and Shephard [54] have identified specific benchmarks regarding $V \mathrm{O}_{\text {2peak }}$ to demonstrate the effects of exercise on aerobic fitness. In sedentary or moderately active individuals suffering from paraplegia, the $V \mathrm{O}_{2 \text { peak }}$ values fluctuate between 20 and $25 \mathrm{ml} \mathrm{kg}^{-1} \mathrm{~min}^{-1}$, while in a group of individuals composed for the most part by wheelchair athletes, these values were approximately $35 \mathrm{ml} \mathrm{kg} \mathrm{min}^{-1}$. Within the group of individuals with SCI at the thoracic and lumbar level not practicing physical activities, the Authors found an extreme variability as regards the values of $V \mathrm{O}_{2 \text { peak. }}$. In this group, about $25 \%$ of the total of the subjects showed $V \mathrm{O}_{2 \text { peak }}$ values less than or equal to $15 \mathrm{ml} \mathrm{kg}^{-1} \mathrm{~min}^{-1}$. Hjeltnes and Janssen [55] found that only $29 \%$ of the population with a $V \mathrm{O}_{2 \text { peak }}$ lower than or equal to $15 \mathrm{ml} \mathrm{kg}^{-1} \mathrm{~min}^{-1}$ was able to independently perform activities of daily life. The percentage of individuals independent in the activities of daily life reached the total sample $(100 \%)$ in the population with $V \mathrm{O}_{\text {2peak }}$ values higher than $25 \mathrm{ml} \mathrm{kg}^{-1} \mathrm{~min}^{-1}$. In conclusion, the paralympic athletes competing in skill and power Sports can be considered, in term of aerobic fitness, as the untrained individuals with high levels of moderate-to-vigorous physical activity (140 min/week), observed by Nightingale et al. [28], and they probably have a better risk profile than sedentary subjects, but significantly worse than the paralympic athletes competing in endurance sports, in whom the high aerobic fitness is associated with a lower ACVD-risk profile.

\section{Limitations}

The study has some limitations. First of all, the cross-sectional design does not allow conclusions on the causative protective role of aerobic fitness against cardiovascular risk and a prospective evaluation through Randomized Clinical Trials needs to confirm this hypothesis. Second, the limited number of paralympic athletes recruited does not allow inferences on the protective role of the practiced sports. Third, classifying obesity with BMI and waist circumference, which are surrogates of body composition, is not standardized in non-ambulatory individuals, and particularly in paralympic athletes. However, at our best knowledge, assessment of overweight and obesity through standard evaluations, such as skin-fold measurements, is lacking for paralympic athlete population.

Finally, data on daily energy balance, i.e., dietary intake and energy expenditure through physical activity, were collected but not processed and reported in this study; therefore, the impact of this variable on cardiovascular risk profile was not evaluated.

\section{Conclusions}

Our results suggest that aerobic fitness could play a crucial role in reducing the cardiovascular risk profile in subjects with locomotor impairment, along with dietary factors as demonstrated by other authors [28]. In fact, obesity and dyslipidemia/hyperglycemia are more frequent in the power or skill-based athletes than the other groups. They have an average $V O_{2 \text { peak }}$ as high as untrained individuals with high levels of moderate-to-vigorous physical activity, evaluated by other Authors [28], and such a level of fitness is probably not enough to reduce cardiovascular risk in both situations. Actually, our results suggest the need for high-level aerobic fitness, with high $V \mathrm{O}_{2 \text { peak }}$ values (similar to those obtained in able-bodied persons [20, $23,24]$ ), which, in our series, are only achieved by endurance athletes. Sports performed at high intensities and which determine high-energy expenditures [35] improve the aerobic fitness [37] based on improvement of both the peripheral extraction of oxygen and, also in athletes with SCI, the cardio-circulatory function [56]. Therefore, these sports seem able to counteract the ACVD-risk profile and potentially reduce the risk of diabetes, heart attack, and stroke. The practice of these sports, but also that of intermittent sports, in which exercise intensity ranges around $70 \%$ of the $V_{2 \text { peak }}$ [35], should be able to offer a protection against atherosclerotic disease in individuals with locomotor impairment. The prescription of physical exercise at the appropriate intensities and the encouragement to carry out sports activities with specific metabolic characteristics must become a fundamental medical practice that Exercise Scientists and Sports Medicine Physician should follow, as suggested by some authors [57, 58]. In this way, at the light of a previous accurate health assessment [12, 39], Exercise and Sport Sciences will become a way to promote health among people with a locomotor impairment [18, 59]. 
Funding Open access funding provided by Università degli Studi dell'Aquila within the CRUI-CARE Agreement.

\section{Compliance with ethical standards}

Conflict of interest Marco Bernardi: no conflict of interest. Silvio Romano: no conflict of interest. Maria Rosaria Squeo: no conflict of interest. Emanuele Guerra: no conflict of interest. Paolo Emilio Adami: no conflict of interest. Federica Alviti: no conflict of interest Antonella Mattei: no conflict of interest. Loretta Corsi: no conflict of interest. Riccardo Lanzano: no conflict of interest. Pietro Giacomo Curatulo: no conflict of interest. Dimitri Mandolesi: no conflict of interest. Fabiana Parisi: no conflict of interest. Barbara Di Giacinto: no conflict of interest. Donatella Dante: no conflict of interest. Claudio Marini: no conflict of interest. Evgeny Mashkovskiy: no conflict of interest. Francisco Javier Ordonez: no conflict of interest. Antonio Spataro: no conflict of interest.

Informed consent Informed consent was obtained from all individual participants included in the study.

Ethical approval All procedures performed in this study were in accordance with the ethical standards of the institutional and/or national research committee (Ethics Committee of the Italian National Olympic Committee) and with the 1964 Helsinki Declaration and its later amendments or comparable ethical standards.

Open Access This article is licensed under a Creative Commons Attribution 4.0 International License, which permits use, sharing, adaptation, distribution and reproduction in any medium or format, as long as you give appropriate credit to the original author(s) and the source, provide a link to the Creative Commons licence, and indicate if changes were made. The images or other third party material in this article are included in the article's Creative Commons licence, unless indicated otherwise in a credit line to the material. If material is not included in the article's Creative Commons licence and your intended use is not permitted by statutory regulation or exceeds the permitted use, you will need to obtain permission directly from the copyright holder. To view a copy of this licence, visit http://creativecommons.org/licenses/by/4.0/.

\section{References}

1. Thom T, Haase N, Rosamond W et al (2006) Heart disease and stroke statistics-2006 update: a report from the American Heart Association Statistics Committee and Stroke Statistics Subcommittee. Circulation 113(6):e85-151

2. Garshick E, Kelley A, Cohen SA, Garrison A, Tun CG, Gagnon $\mathrm{D}$ et al (2005) A prospective assessment of mortality in chronic spinal cord injury. Spinal Cord 43(7):408-416

3. Bauman WA, Spungen AM (2008) Coronary heart disease in individuals with spinal cord injury: assessment of risk factors. Spinal Cord 46:466-476

4. Yekutiel M, Brooks ME, Ohry A, Yarom J, Carel R (1989) The prevalence of hypertension, ischemic heart disease and diabetes in traumatic spinal cord injured patients and amputees. Paraplegia 27:58-62

5. Naschitz JE, Lenger R (2008) Why traumatic leg amputees are at increased risk for cardiovascular diseases. QJM 101(4):251-259. https://doi.org/10.1093/qjmed/hcm131
6. Perkins ZB, De'Ath HD, Sharp G, Tai NR (2012) Factors affecting outcome after traumatic limb amputation. Br J Surg 99(Suppl 1):75-86. https://doi.org/10.1002/bjs.7766

7. Krause JS, Cao Y, DeVivo MJ, DiPiro ND (2016) Risk and protective factors for cause-specific mortality after spinal cord injury. Arch Phys Med Rehabil 97:1669-1678

8. Bauman WA, Spungen AM, Shong YG, Rothstein JL, Petry C, Gordon SK (1992) Depressed serum high density lipoprotein cholesterol level in veterans with spinal cord injury. Paraplegia 30:697-703

9. Lai YJ, Lin CL, Chang YJ, Lin MG, Lee ST, Sung FC, Lee WY, Kao CH (2014) Spinal cord injury increases the risk of Type 2 diabetes: a population-based cohort study. Spine J 14:1957-1964

10. Jacobs PL, Nash MS (2004) Exercise recommendations for individuals with spinal cord injury. Sport Med 34(11):727-751

11. Myers J, Lee M, Kiratli J (2007) Cardiovascular disease in spinal cord injury: an overview of prevalence, risk, evaluation, and management. Am J Phys Med Rehabil 86(2):142-152

12. Egidi F, Faiola F, Guerra E, Marini C, Sardella F, Bernardi M (2009) Sport for disabled individuals: from rehabilitation to Paralympic Games. Med Sport 62(4):597-601

13. Palmieri V, Spataro A, Bernardi M (2010) Cardiovascular eligibility in specific conditions: the paralympic athlete. Med Sport 63(1):95-101

14. Krause JS, Kjorsvig JM (1992) Mortality after spinal cord injury: a four prospective study. Arch Phys Med Rehab 73:558-563

15. Fernhall B, Heffernan K, Jae SY, Hedrick B (2008) Health implications of physical activity in individuals with spinal cord injury: a literature review. J Health Hum Serv Adm 30:468-502

16. Ordonez FJ, Rosety MA, Camacho A, Rosety I, Diaz AJ, Fornieles G, Bernardi M, Rosety-Rodriguez M (2013) Arm-cranking exercise reduced oxidative damage in adults with chronic spinal cord injury. Arch Phys Med Rehabil 94(12):2336-2341. https:// doi.org/10.1016/j.apmr.2013.05.029

17. Rosety-Rodriguez M, Camacho A, Rosety I, Fornieles G, Rosety MA, Diaz AJ, Bernardi M, Ordonez FJ (2014) Low-grade systemic inflammation and leptin levels were improved by arm cranking exercise in adults with chronic spinal cord injury. Arch Phys Med Rehabil 95(2):297-302. https://doi.org/10.1016/j. apmr.2013.08.246

18. Martin Ginis KA, van der Scheer JW, Latimer-Cheung AE, Barrow A, Bourne C, Carruthers P, Bernardi M, Ditor DS, Gaudet S, de Groot S, Hayes KC, Hicks AL, Leicht CA, Lexell J, Macaluso S, Manns PJ, McBride CB, Noonan VK, Pomerleau P, Rimmer JH, Shaw RB, Smith B, Smith KM, Steeves JD, Tussler D, West CR, Wolfe DL, Goosey-Tolfrey VL (2018) Evidence-based scientific exercise guidelines for adults with spinal cord injury: an update and a new guideline. Spinal Cord 56(4):308-321. https:// doi.org/10.1038/s41393-017-0017-3

19. Tweedy SM, Beckman EM, Geraghty TJ, Theisen D, Perret C, Harvey LA, Vanlandewijck YC (2017) Exercise and sports science Australia (ESSA) position statement on exercise and spinal cord injury. J Sci Med Sport 20(2):108-115. https://doi.org/10.1016/j. jsams.2016.02.001(Epub 2016 Mar 9)

20. Sassen B, Cornelissenc VA, Kiersa H, Wittinka H, Kokb G, Vanhees L (2009) Physical fitness matters more than physical activity in controlling cardiovascular disease risk factors. Eur J Cardiovasc Prev Rehabil 16:677-683

21. Myers J, Prakash M, Froelicher V, Do D, Partington S, Edwin Atwood J (2002) Exercise capacity and mortality among men referred for exercise testing. N Engl J Med 346(11):793-801

22. van der Velde JHPM, Savelberg Hans HCM,. Schaper NC, Koster A. (2015) Moderate activity and fitness, not sedentary time, are independently associated with cardio-metabolic risk in U.S. adults aged 18-49. Int. J. Environ. Res. Public Health, 12, 2330-2343; doi:https://doi.org/10.3390/ijerph120302330 
23. Ekblom O, Ekblom-Bak E, Rosengren A, Hallsten M, Bergström G, Börjesson M (2015) Cardiorespiratory fitness, sedentary behaviour and physical activity are independently associated with the metabolic syndrome, results from the SCAPIS Pilot Study. PlosOne. https://doi.org/10.1371/journal.pone.0131586Jun e29,2015

24. Knaeps S, Lefevre J, Wijtzes A, Charlier R, Mertens E, Bourgois JG (2016) Independent associations between sedentary time, moderate-to-vigorous physical activity, cardiorespiratory fitness and cardio-metabolic health: a cross-sectional study. PLoS ONE 11(7):e0160166. https://doi.org/10.1371/journal.pone.0160166

25. Clausen JSR, Marott JL, Holtermann A, Gyntelberg F, Jensen MT (2018) Midlife cardiorespiratory fitness and the long-term risk of mortality: 46 years of follow-up. JACC 72(9):987-995. https:// doi.org/10.1016/j.jacc.2018.06.045

26. Satoru Kodama S, Saito K, Tanaka S, Maki M, Yachi Y, Asumi M, Sugawara A, Totsuka K, Shimano H, Ohashi Y, Yamada N, Sone $\mathrm{H}$ (2009) Cardiorespiratory fitness as a quantitative predictor of all-cause mortality and cardiovascular events in healthy men and women: a meta-analysis. JAMA 301(19):2024-2035. https://doi. org/10.1001/jama.2009.681

27. Nightingale TE, Bilzon J (2016) Cardiovascular health benefits of exercise in people with spinal cord injury: more complex than a prescribed exercise untervention? Arch Phys Med Rehabil 97:1038-1040

28. Nightingale TE, Walhin JP, Thompson D, Bilzon JLJ (2019) Biomarkers of cardiometabolic health are associated with body composition characteristics but not physical activity in persons with spinal cord injury. J Spinal Cord Med 42(3):328-337. https://doi. org/10.1080/10790268.2017.1368203

29. Figoni SF, Dolbow DR, Crawford EC, White ML, Pattanaik S (2020) Does aerobic exercise benefit persons with tetraplegia from spinal cord injury? A systematic review. J Spinal Cord Med 11:1-14. https://doi.org/10.1080/10790268.2020.1722935

30. Webborn N, Van De Vliet P (2012) Paralympic medicine. Lancet 379:65-71

31. Bhambhany Y (2002) Physiology of wheelchair racing in athletes with spinal cord injury. Sport Med 32:23-51

32. Pepper M, Willick S (2009) Maximizing physical activity in athletes with amputations. Curr Sports Med Rep 8:339-344

33. Filho JAO, Salvetti XM, de Mello MT, da Silva AC, Filho BL (2006) Coronary risk in a cohort of Paralympic athletes. Br J Sports Med 40:918-922

34. Bernardi M, Fedullo AL, Di Giacinto B, Squeo MR, Aiello P, Dante D, Romano S, Magaudda L, Peluso I, Palmery M, Spataro A (2019) Cardiovascular risk factors and haematological indexes of inflammation in paralympic athletes with different motor impairments. Oxid Med Cell Longev. https://doi. org/10.1155/2019/6798140

35. Bernardi M, Guerra E, Di Giacinto B, Di Cesare A, Castellano V, Bhambhani Y (2010) Field evaluation of Paralympic athletes in selected sports: implications for training. Med Sci Sports Exerc 42(6): 1200-1208

36. Price M (2010) Energy expenditure and metabolism during exercise in persons with a spinal cord injury. Sports Med 40(8):681-696

37. Bernardi M, Carucci S, Faiola F, Egidi F, Marini C, Castellano V, Faina M (2012) Physical fitness evaluation of Paralympic winter sports sitting athletes. Clin J Sport Med 22(1):26-30 (Erratum in Clin J Sport Med. 2012 Mar;22(2):209)

38. Baumgart JK, Brurok B, Sandbakk Ø (2018) Peak oxygen uptake in Paralympic sitting sports: a systematic literature review, metaand pooled-data analysis. PLoS ONE 13(2):e0192903. https://doi. org/10.1371/journal.pone.0192903
39. Pelliccia A, Quattrini FM, Squeo MR, Caselli S, Culasso F, Link MS, Spataro A, Bernardi M (2016) Cardiovascular diseases in Paralympic athletes. Br J Sports Med 50(17):1075-1080. https ://doi.org/10.1136/bjsports-2015-095867[Epub ahead of print: bjsports-2015-095867]

40. Pelliccia A, Maron BJ (1995) Preparticipation cardiovascular evaluation of the competitive athlete: perspectives from the 30-year Italian experience. Am J Cardiol 75:827-829

41. Adami PE, Delussu AS, Squeo MR, Corsi L, Rodio A, Fattorini L, Quattrini FM, Bernardi M (2015) Upper limb aerobic training improves aerobic fitness and all-out performance of America's Cup grinders. Eur J Sports Sci 15(3):235-241. https://doi. org/10.1080/17461391.2014.971878

42. Chobanian AV (2003) Joint National Committee on prevention, detection, evaluation and treatment of high blood pressure. Seventh report. JAMA 289:2560-2572

43. Obesity: preventing and managing the global epidemic. Report of a WHO Consultation (WHO Technical Report Series) (Geneva, 2000) ISBN: 924120894 5, ISSN 0512-3054

44. Rice I, Hettinga FJ, Laferrier J, Sporner ML, Heiner CM, Burkett B, Cooper RA (2011) Biomechanics. In: Vanlandewijck YC, Thompson WR (eds) Handbook of sports medicine and sciencethe paralympic athlete, Chapter 2. Wiley-Blackwell, Chichester, pp 33-50

45. Goll M, Wiedemann MSF, Spitzenpfeil P (2015) Metabolic demand of Paralympic alpine skiing in sit-skiing athletes. J Sports Sci Med 14:819-824

46. Teasell RW, Arnold JM, Krassioukov A, Delaney GA (2000) Cardiovascular consequences of loss of supraspinal control of the sympathetic nervous system after spinal cord injury. Arch Phys Med Rehabil 81(4):506-516

47. Blackmer J (1997) Orthostatic hypotension in spinal cord injured patients. J Spinal Cord Med 20(2):212-217

48. Saunders LL, Krause JS, Saladin M, Carpenter MJ (2015) Prevalence of cigarette smoking and attempts to quit in a populationbased cohort with spinal cord injury. Spinal Cord 53:641-645

49. Bunten DC, Warner AL, Brunnemann SR, Segal JL (1998) Heart rate variability is altered following spinal cord injury. Clin Auton Res 8(6):329-334

50. Bernardi M, Fontana G, Rodio A, Madaffari A, Brugnoli M, Quattrini FM, Marchetti M (2007) Physiological characteristics of America's Cup sailors. J Sports Sci 25(10):1149-1160

51. Bernardi E, Delussu SA, Quattrini FM, Rodio A, Bernardi M (2007) Energy balance and dietary habits of America's Cup sailors. J Sports Sci 25(10):1161-1168

52. Bernardi E, Bernardi M, Berni CR, Branca F, Garbagnati F, Scogliamiglio U, Traballesi M, Bertini I, Giampietro M, Cairella G (2005) L'alimentazione nell'atleta disabile motorio (Nutrition in athletes with motor disabilities). Med Sport 58(4):289-301

53. Totosy de Zepetnek JO, Pelletier CA, Hicks AL, MacDonald MJ (2015) Following the physical activity guidelines for adults with spinal cord injury for 16 weeks does not improve vascular health: a randomized controlled trial. Arch Phys Med Rehabil 96(9):1566-1575. https://doi.org/10.1016/j.apmr.2015.05.019

54. Noreau L, Shephard RJ (1995) Spinal cord injury, exercise and quality of life. Sports Med 20(4):226-250

55. Hjeltnes N, Jansen T (1990) Physical endurance capacity, functional status and medical complications in spinal cord injured subjects with long-standing lesion. Paraplegia 28(7):428-432

56. Bernardi M, Guerra E, Rodio A, Dante D, Castellano V, Peluso I, Schena F, Bhambhani Y (2020) Assessment of exercise stroke volume and its prediction from oxygen pulse in paralympic athletes with locomotor impairments: cardiac long-term adaptations are possible. Front Physiol 10:1451. https://doi.org/10.3389/fphys .2019 .01451 
57. Nightingale TE, Metcalfe RS, Vollaard NB, Bilzon JL (2017) Exercise guidelines to promote cardiometabolic health in spinal cord injured humans: time to raise the intensity? Arch Phys Med Rehabil 98:1693-1704

58. Krassioukov AV, Currie KD, Hubli M, Nightingale TE, Alrashidi AA, Ramer L, Eng JJ, Martin Ginis KA, MacDonald MJ, Hicks A, Ditor D, Oh P, Verrier MC, Craven BC (2019) (2019) Effects of exercise interventions on cardiovascular health in individuals with chronic, motor complete spinal cord injury: protocol for a randomised controlled trial [Cardiovascular Health/ Outcomes: Improvements Created by Exercise and education in SCI (CHOICES) Study]. BMJ Open 9:e023540. https://doi. org/10.1136/bmjopen-2018-023540
59. Blauwet C, Willick SE (2012) The Paralympic Movement: using sports to promote health, disability rights, and social integration for athletes with disabilities. PM\&R 4(11):851-856. https://doi. org/10.1016/j.pmrj.2012.08.015

Publisher's Note Springer Nature remains neutral with regard to jurisdictional claims in published maps and institutional affiliations. 